\title{
Male reproductive success during spawning events of the octocoral Pseudopterogorgia elisabethae
}

\author{
Howard R. Lasker ${ }^{1,2, *}$, Carla Gutiérrez-Rodríguez ${ }^{3,4}{ }^{\text {, }}$ Katherine Bala ${ }^{1}$, \\ Andrew Hannes ${ }^{3,5}$, Jaret P. Bilewitch ${ }^{2}$ \\ ${ }^{1}$ Graduate Program in Evolution, Ecology and Behavior, ${ }^{2}$ Department of Geology, and ${ }^{3}$ Department of Biological Sciences, \\ University at Buffalo, Buffalo, New York 14260, USA \\ ${ }^{4}$ Departamento de Biología Evolutiva, Instituto de Ecología, A.C., Km 2.5 antigua carretera a Coatepec No. 351, \\ Congregación El Haya, Xalapa, Veracruz 91070, México \\ ${ }^{5}$ Marine Science and Biological Research, Coastal Planning and Engineering Inc., Boca Raton, Florida 33431, USA
}

\begin{abstract}
Many sessile organisms rely on the transport of one or both types of gametes for reproductive success. While sperm limitation has been reported in some species, high fertilization success has been observed in others including the branching octocoral Pseudopterogorgia elisabethae. In such cases, males may compete for eggs to fertilize and the local dispersion of sperm will be an important component of male success. Individual reproductive success of 91 male $P$. elisabethae colonies found within a $400 \mathrm{~m}^{2}$ area on San Salvador Island, Bahamas was examined based on microsatellite analysis of planulae collected from female colonies. Larvae which were brooded on the surface of 4 different females were collected during 2 separate spawning events. Males in the study area were sampled, and parentage was assessed using 5 microsatellite loci and the paternity assignment program CERVUS 3.0. Twenty-five percent of the larvae were assigned sires with $\geq 80 \%$ likelihood and $87 \%$ of the planulae could have been sired by males within the study area. The success of males was not related to either distance to the female or to male colony size. On average, successful sperm only travelled $5.2 \mathrm{~m}$ and the success of individual males within the $400 \mathrm{~m}^{2}$ study site was not significantly different from random expectations. Male $P$. elisabethae may follow spawning strategies that increase the likelihood of siring some planulae, spread success across multiple females and reduce variance in reproductive success.
\end{abstract}

KEY WORDS: Gorgonian coral $\cdot$ Microsatellites $\cdot$ Paternity $\cdot$ Sperm $\cdot$ Dispersal $\cdot$ Male reproductive success

Resale or republication not permitted without written consent of the publisher

\section{INTRODUCTION}

The recognition that syngamy is not assured in broadcast spawning marine organisms (Pennington 1985) ushered in 2 decades of investigation on both the ecological and evolutionary effects of searching for a mate. Most studies of broadcast spawning have focused on female fertilization success, i.e. factors affecting the proportion of eggs that are fertilized. Female fertilization success depends on the proximity to males (Pennington 1985, Yund 1990, Brazeau \& Lasker 1992), population density (Levitan 1991, Levitan et al. 1992,
Coma \& Lasker 1997a), gamete age (Oliver \& Babcock 1992), and flow regime (Pennington 1985, Yund 1990, Levitan et al. 1992, Petersen et al. 1992, Sewell et al. 1992, Lasker et al. 1996, Coma \& Lasker 1997b). A corollary to these results is that factors that affect fertilization success in females should also affect the relative success of males contributing sperm to the spawning event. For instance, differences in size and positioning relative to females, and the prevailing currents should affect the relative success of males.

Few studies have directly assessed sperm dispersal and its effects on male reproductive success. These 
studies have typically been based on paternity analysis of embryos produced in controlled matings involving only a few individuals (Yund \& McCartney 1994, Yund 1995). The only study examining paternity in a natural spawning event (Coffroth \& Lasker 1998) examined a population of the octocoral Plexaura kuna, in which there were only a few potential sires. Although these studies provide insights into the factors controlling mating patterns, they do not address sperm dispersal and reproductive success in most natural populations in which numerous males are present.

The development of highly polymorphic DNA genetic markers such as microsatellites, has increased the possibility of assessing paternity within local populations containing multiple males. For instance, a large number of investigations in plants have used microsatellites to estimate the contribution of pollen dispersal to gene flow, and to assess mating patterns and male reproductive success in natural plant populations (Dow \& Ashley 1998, Streiff et al. 1999, Konuma et al. 2000, Lian et al. 2001). In this study, we used microsatellites to assess male reproductive success and sperm dispersal in a population of the branching octocoral Pseudopterogorgia elisabethae.

Pseudopterogorgia elisabethae is a gorgoniid alcyonacean with gonochoric colonies, and is common in many reefs throughout the Caribbean. In the Bahamas, $P$. elisabethae spawns once or twice each year, in November to December or December to January (Gutiérrez-Rodríguez \& Lasker 2004a). Females are surface brooders, i.e. they retain eggs on their surface where the eggs are fertilized, develop into planulae and are then washed off the colony after several days. The release of sperm can be inferred by the disappearance of spermaries from male polyps coincident with the days on which females have eggs exposed on their surface. (Gutiérrez-Rodríguez \& Lasker, 2004a). Sperm release has never been observed, but is presumed to occur in the mornings when eggs are spawned. Lasker (2006) suggested that surface brooding may be advantageous, as it removes the necessity of closely synchronizing the release of gametes by colonies. Since eggs remain on the surface of females, sperm from upstream males can effect fertilization as long as the eggs are receptive. While that may account for the high levels of fertilization observed, success of males and the factors that control their relative success are unknown for $P$. elisabethae and for benthic species in general.

Surface brooding is a relatively rare trait among benthic invertebrates, and the only other study directly relevant to Pseudopterogorgia elisabethae is that conducted on Briareum asbestinum. Brazeau \& Lasker (1992) found that fertilization success of B. asbestinum, which is also an octocoral and a gonochoric brooder like $P$. elisabethae, was weakly correlated with the density of nearby males up to $3 \mathrm{~m}$ away. Their results suggest that, while distance can be important on a small scale, there may be a maximum distance beyond which male success is effectively zero. Bishop \& Pemberton (2006) examined somewhat analogous systems in bryozoans and tunicates and argued that these groups are highly efficient in achieving high fertilization success even when sperm density is low. The bryozoans and tunicates examined in their study actively pump water through the zooids, which should enhance fertilization success. In laboratory and field manipulations, researchers examining such systems have identified variance in male success associated with distance to the female (Yund \& McCartney 1994) and effects of timing (i.e. precedence) (Marshall et al. 2004). However, Johnson \& Yund (2007) found that the estimate of the minimum number of males fertilizing broods of the tunicate Botryllus schlosseri did not vary between high and low density populations. Ayre \& Miller (2006) reported genetic diversity that is consistent with multiple paternity in broods of a scleractinian in which colonies were scattered over several meters, and Yund et al. (2007) found that fertilization of B. schlosseri eggs could occur over distances as far as $207 \mathrm{~m}$.

The reproductive characteristics of Pseudopterogorgia elisabethae and studies of fertilization in marine invertebrates in general lead to the following questions about male spawning, which we address in this study: How variable is male reproductive success? Are males close to females more successful in siring larvae than males farther away? Over what distances do males effectively mate with females? Do male size and sperm production affect the number of eggs a male fertilizes?

\section{MATERIALS AND METHODS}

Field methods. Samples used in this study were collected from a reef at $10 \mathrm{~m}$ depth on San Salvador Island, Bahamas. The reef, locally identified as Pillar Reef, is located north of Riding Rock Point on the west coast of the island. The study site was a cluster of Pseudopterogorgia elisabethae colonies found within a $20 \times 20 \mathrm{~m}$ area on a spur of the reef. The site was bounded by sand on one side and by reef containing very few $P$. elisabethae colonies on the other side. Beyond the $400 \mathrm{~m}^{2}$ area, the closest $P$. elisabethae colonies were an additional $10 \mathrm{~m}$ away. All colonies within the area were marked, their heights measured, and tissues sampled. Tissue samples ( 16 cm in length) from all the colonies in the study site were collected prior to spawning, and the samples were dissected and examined under magnification at $40 \times$ to determine which colonies were males. A map of the area was generated by marking colony positions after determin- 
ing distances and compass headings between colonies. Coordinates of the colonies were then used to determine male to female colony distances. Spawning was monitored in November 1998 and December 1999, with larvae collected from female colonies that had released many eggs. Two different female colonies were selected in each year of the study. After spawning, embryos were allowed to develop into planulae on the surfaces of the female colonies, after which they were collected with syringes and preserved in $95 \%$ ethanol. A total of 181 planulae were preserved (39 from female 924 and 33 from female 913 in 1998, and 52 from female 1389 and 57 from female 1394 in 1999). Tissue samples $(\sim 6 \mathrm{~cm})$ from each of 104 male colonies and from the 4 females whose planulae were sampled, were preserved in $95 \%$ ethanol for genetic analyses.

Microsatellite analysis. DNA was extracted from the planulae and from 1 to $3 \mathrm{~cm}$ of tissue samples from each of the males and females using either a modification (Shearer et al. 2005) of the manufacturer's protocol for the Prep-A-Gene DNA extraction kit (Bio-Rad Laboratories) or the CTAB method described in Coffroth et al. (1992). Paternity analyses were based on 5 microsatellite loci: Pel-1 which is located in the ITS region; Pel-19 and Pel-32 which are described in GutiérrezRodríguez \& Lasker (2004b,c); and Pel-62 and Pel-84 which were developed for this study from the previously developed cloned genomic library described in Gutiérrez-Rodríguez \& Lasker (2004b). The sequences of $5^{\prime}$ and $3^{\prime}$ flanking regions of potential microsatellite loci were compared to each other and to sequences obtained for the 3 previous loci to ensure each represented a unique locus, and primers flanking the microsatellites were designed. Genomic DNA extracted from adult colonies was amplified to ensure polymorphism and assess allelic diversity.

DNA from all of the planulae and the sampled adults was amplified with primers for the 5 microsatellite loci. Sample amplification at loci Pel-19 and Pel-32 was conducted in 2000 and at Pel-1, Pel-62 and Pel-84 in
2006 and 2007. Material for 10 of the male colonies was no longer available for analysis with loci Pel-1, Pel-62 and Pel-84. PCR reactions were conducted in $10 \mu \mathrm{l}$ volumes containing $1 \mu \mathrm{l}$ of template DNA, and 2 units of Taq polymerase, in final concentrations of $10 \mathrm{mM}$ Tris (pH 8.3), $50 \mathrm{mM} \mathrm{KCl}, 2.5 \mathrm{mM} \mathrm{MgCl}, 0.025 \mu \mathrm{M}$ of forward primer (with a 5' M13 complementary 'tail', 5'-CACGACGTTGTAAAACGAC-3'), $0.05 \mu \mathrm{M}$ of reverse primer, $0.025 \mu \mathrm{M}$ of fluorescently labeled M13 primer (LI-COR Biotechnology Division), and $50 \mathrm{mM}$ of each dNTP (Fermentas) on a MJ Research PTC-100 thermocycler (MJ Research). Other locus-specific PCR conditions for Pel-62 and Pel-84 are given in Table 1. Similar data for Pel-1, Pel-19 and Pel-32 are presented in Gutiérrez-Rodríguez \& Lasker (2004a,b).

Fluorescently labeled PCR products were visualized on $7 \%$ denaturing polyacrylamide gels using a LI-COR NEN ${ }^{\circledR}$ Global IR2 DNA Sequencer. The genotype of each individual was determined by comparing the migration of the alleles to that of 4 standard 50 to $350 \mathrm{bp}$ DNA ladders (LI-COR Biotechnology Division) spaced uniformly across the gel. Allele sizes were determined using the computer program Gene ImagIR version 4.03 (Scanalytics ). PCR product sizes were verified by measuring distances between density peaks in comparison with size standards using the program ImageJ (NIH).

Independence of all 5 loci was assessed by testing for linkage disequilibrium using FSTAT version 2.9.3 (Goudet 1995). The expected and observed heterozygosity, adherence to Hardy-Weinberg expectation, and the number of alleles were obtained using GENEPOP (Raymond \& Rousset 1995) and FSTAT (Goudet 1995). CERVUS 3.0 (Kalinowski et al. 2007) and Microchecker version 2.2.3 (van Oosterhout et al. 2004) were used to detect null alleles. Paternity assignments were made using the parentage analysis program CERVUS 3.0, which uses a likelihood approach to assign paternity. Simulations in the program were run for 10000 cycles. Unavailability of 10 samples in the 2006 laboratory analyses and failure of 3 others to

Table 1. Pseudopterogorgia elisabethae. Characteristics of loci Pel-62 and Pel-84 and PCR conditions for their amplification. Number of alleles and size range based on surveys of over 600 ind. from 12 sites in the Bahamas and Florida. Fwd: forward; Rvs: reverse

\begin{tabular}{|c|c|c|c|c|c|c|c|c|c|c|}
\hline Locus & $\begin{array}{l}\text { Primer sequences } \\
\left(5^{\prime}-3^{\prime}\right)\end{array}$ & $\begin{array}{c}\text { Repeat of } \\
\text { cloned allele }\end{array}$ & $\begin{array}{l}\text { Initial } \\
\text { denature }\end{array}$ & Denature & Anneal & Extend & $\begin{array}{l}\text { No. of } \\
\text { cycles }\end{array}$ & $\begin{array}{c}\text { Final } \\
\text { extension }\end{array}$ & $\begin{array}{l}\text { No. of } \\
\text { alleles }\end{array}$ & $\begin{array}{c}\text { Allele } \\
\text { size range }\end{array}$ \\
\hline Pel-62 & $\begin{array}{l}\text { Fwd: ACT TCG CCT } \\
\text { TGG CTG TTA GTC } \\
\text { Rvs: GCA AAA TTC } \\
\text { CAG CTA GTG TT }\end{array}$ & $(\mathrm{CAAACA})_{22}$ & $95^{\circ} \mathrm{C} / 3 \mathrm{~min}$ & $94 / 45 \mathrm{~s}$ & $57 / 45 \mathrm{~s}$ & $72 / 30 \mathrm{~s}$ & 32 & $72^{\circ} \mathrm{C} / 5 \mathrm{~min}$ & 16 & $118-316 \mathrm{bp}$ \\
\hline Pel-84 & $\begin{array}{l}\text { Fwd: GGT GAA ACA } \\
\text { AGT CCG CAT A } \\
\text { Rvs: GAT CCT AGA } \\
\text { GTT GCA GGT GTC }\end{array}$ & $(\mathrm{GT})_{16}$ & $95^{\circ} \mathrm{C} / 3 \mathrm{~min}$ & $94 / 45 \mathrm{~s}$ & $55 / 45 \mathrm{~s}$ & $72 / 50 \mathrm{~s}$ & 26 & $72^{\circ} \mathrm{C} / 5 \mathrm{~min}$ & 54 & $147-277 \mathrm{bp}$ \\
\hline
\end{tabular}


amplify at some of the loci led to inclusion of only 91 of the 104 males in the analysis. The proportion of males included in the analysis was set at $75 \%$ of the potential males to allow for both the unanalyzed males and the possibility of sires that were outside of the area. The proportion of loci typed was left at the default value, and the genotyping error rate was set to 0.05 which was a more conservative estimate than the default value. CERVUS 3.0 calculates error rates based on mother-offspring mismatches, and there were mismatches involving 2 of the females. However, as there were only 4 females in the analysis, multiple mismatches involving the same female do not provide an independent assessment of scoring error.

Analysis of the genotype data indicated that Female 1389 exhibited a null allele at locus Pel-19. Female 1389 was initially scored as a homozygote at locus Pel-19, but only $51 \%$ of her offspring shared the allele with her. Since half of her offspring did not share this allele, we concluded that the mother was heterozygous, having both the visible allele and an unseen, null allele. The null allele was coded as missing data for the mother and for each of her planulae that did not contain the visible maternal allele. That adjustment did not correct for the large deviation from the HardyWeinberg expectation at that locus in the rest of the population; thus, the paternity analysis was repeated without the Pel-19 locus. Heterozygote deficiencies in Pel-84 at Pillar Reef and in Pel-62 at other Bahamian populations (H. R. Lasker, J. P. Bilewitch unpubl. data), as well as the predicted high frequency of null alleles in both loci (Table 2), suggest that they may also have null alleles; thus, paternity assignments were repeated without data for these loci as well.

Paternity assignments were determined for each planula at 95, 90, 85, 80, 70, 60 and 50\% probabilities. After paternity assignments were made, the successes of the male colonies were compared to each other in terms of the size of the colonies and their distance to the female colonies. Size was analyzed as both height

Table 2. Pseudopterogorgia elisabethae. Characteristics of 5 microsatellite loci among 106 ind. at Pillar Reef, San Salvador, Bahamas

\begin{tabular}{|c|c|c|c|c|c|}
\hline Locus & $\begin{array}{l}\text { No. of } \\
\text { alleles }\end{array}$ & $\begin{array}{c}\text { Gene } \\
\text { diversity }\end{array}$ & $\begin{array}{c}\text { Heteroz } \\
\text { Observed }\end{array}$ & $\begin{array}{l}\text { zygosity } \\
\text { Expected }\end{array}$ & $\begin{array}{l}\text { Null fre- } \\
\text { quency }\end{array}$ \\
\hline Pel-1 & 2 & 0.357 & $0.462^{* *}$ & 0.357 & -0.130 \\
\hline Pel-19 & 10 & 0.804 & $0.510^{* *}$ & 0.790 & 0.215 \\
\hline Pel-32 & 26 & 0.880 & 0.798 & 0.873 & 0.044 \\
\hline Pel-62 & 15 & 0.274 & 0.237 & 0.295 & 0.138 \\
\hline Pel-84 & 47 & 0.961 & $0.865^{*}$ & 0.962 & 0.051 \\
\hline
\end{tabular}

and area (height $\times$ width). Effects of size and distance from the female on whether a male sired any planulae and on numbers of planulae sired were evaluated with logistic regressions.

\section{RESULTS}

\section{Allele frequencies}

Population statistics are based on the 91 male and 4 female colonies analyzed. As previously reported in an analysis of 3 of the loci (Gutiérrez-Rodríguez et al. 2005), the Pseudopterogorgia elisabethae population at Pillar Reef is one of the most genetically diverse populations that has been studied in the Bahamas. Detailed information on the 5 loci is presented in Table 2. As noted above, Pel-19 exhibited a significant heterozygote deficiency ascribable to the presence of null alleles. Pel-84 exhibited similar significant heterozygote deficiencies consistent with the presence of null alleles. Pel-1 also deviated from the Hardy-Weinberg expectation, although there was a heterozygote excess in this case.

\section{Paternity analysis}

A total of 187 planulae were genotyped at 2 or more of the loci and were included in the analysis. Of those planulae, 171 were genotyped at 3 or more loci. Only adults for which 3 or more loci were genotyped were used in the analysis, which reduced the total number of males to 91. The numbers of planulae assigned sires at different confidence levels are presented in Table 3. When all loci were included in the analysis, $25 \%$ of the planulae could be assigned a sire at the $80 \%$ confidence level (i.e. likelihood of $\geq 80 \%$ ). Albeit with much lower certainty, a male could be identified as a 'most likely sire' for a total of $87 \%$ of the planulae. While these other assignments cannot be used in analyses of the success of individual males, they suggest that the males in the $20 \times 20 \mathrm{~m}$ area can account for paternity for the majority of the planulae. However, 37 of the 187 planulae had alleles at 1 locus, and in 3 cases at 2 of the loci, that were not present in the known male genotypes. The previously unidentified alleles were in Pel-19 (2 alleles), Pel-32 (5 alleles), Pel-62 (6 alleles) and Pel-84 (5 alleles). Thus, a minimum of 6 additional males successfully sired planulae. Those males were either outside the study area and/or were among the 13 males from the study site whose complete genotypes were unknown.

The likelihood analyses used to assign paternity assume populations are in Hardy-Weinberg equilib- 
Table 3. Pseudopterogorgia elisabethae. Number of planulae (with percentage in parentheses) assigned a sire with CERVUS 3.0 at different confidence levels in analyses containing all 5 loci compared with analyses in which some loci were excluded

\begin{tabular}{|c|c|c|c|c|c|c|}
\hline Confidence level (\%) & All loci & $\begin{array}{c}\text { Pel-1 } \\
\text { excluded }\end{array}$ & $\begin{array}{l}\text { Pel-19 } \\
\text { excluded }\end{array}$ & $\begin{array}{c}\text { Pel-62 } \\
\text { excluded }\end{array}$ & $\begin{array}{c}\text { Pel-84 } \\
\text { excluded }\end{array}$ & $\begin{array}{l}\text { Pel-19 \& Pel-62 } \\
\text { excluded }\end{array}$ \\
\hline 95 & $5(3)$ & $7(4)$ & $6(3)$ & $4(2)$ & $3(2)$ & 1 (1) \\
\hline 90 & 19 (10) & 21 (11) & $19(11)$ & 21 (11) & $3(2)$ & $7(4)$ \\
\hline 85 & 33 (18) & 30 (16) & $36(21)$ & 30 (16) & $12(6)$ & 24 (14) \\
\hline 80 & $46(25)$ & $47(25)$ & $42(24)$ & $38(20)$ & $19(10)$ & $41(24)$ \\
\hline 70 & $63(34)$ & 61 (33) & 66 (38) & 64 (34) & $26(14)$ & 57 (33) \\
\hline 60 & $102(55)$ & $97(52)$ & $88(51)$ & $103(55)$ & 31 (17) & $71(42)$ \\
\hline 50 & $151(81)$ & $153(82)$ & $105(60)$ & $143(76)$ & $50(27)$ & $94(55)$ \\
\hline All planulae that could be assigned a sire & $163(87)$ & $163(98)$ & $126(72)$ & $159(85)$ & $153(82)$ & $116(68)$ \\
\hline Total analyzed (2 or more loci scored) & 187 & 166 & 174 & 187 & 187 & 171 \\
\hline Non-exclusion probability & 0.0060 & 0.0070 & 0.0149 & 0.0073 & 0.071 & 0.0180 \\
\hline $\begin{array}{l}\text { Number of planulae with alleles not present } \\
\text { among known males in the population }\end{array}$ & 37 & 37 & 36 & 18 & 31 & 16 \\
\hline
\end{tabular}

rium. Three of the 5 loci exhibited significant deviations from Hardy-Weinberg equilibrium (Table 2). As noted, the genotypes of Female 1389 and her offspring were adjusted to include the evidence that she was a heterozygote with a null allele at Pel-19. However, there is no simple mechanism for making such adjustments in the genotypes of other apparent homozygotes in the population. To test for the robustness of the result, the analyses were repeated 4 times, each time dropping one of the loci that was out of HardyWeinberg equilibrium or that had a predicted high frequency of null alleles. Removing either Pel-1 or Pel-19 had relatively little effect on the paternity assignments. Reducing the number of included loci led to fewer assignments (Table 3), but with the same male being identified as the sire in all cases wherein an assignment was made ( $80 \%$ confidence in both analyses). Thus, removing the locus with the greatest predicted null allele frequency did not change the results on the relative success of individual males. Removing Pel-84 which was the most polymorphic of the loci, had a greater effect. Fewer assignments could be made at the $80 \%$ likelihood level, and 4 of the 12 assignments changed. This is not surprising, given the high genotypic diversity of $\mathrm{Pel}-84$ and the high non-exclusion probability (0.07) of the analysis when Pel-84 was removed. Removing Pel-62 from the analysis yielded an intermediate number of assignments, but the assignments made at $80 \%$ confidence level were identical to those made when all 5 loci were included in the analysis.

Using all 5 loci and a confidence level of $80 \%$, sires were assigned to 46 of the 171 planulae. Out of 91 males for which there were sufficient genotype data, 26 were identified as sires (Table 4). Eight males sired more than a single planula, with 5 and 2 males siring planulae on different colonies and in both years of observation, respectively. Averaged across all of the females, the distance travelled by a successful sperm was $5.2 \mathrm{~m}( \pm 3.1 \mathrm{SD})$ with a range of 0.8 to $11.8 \mathrm{~m}$. These distances are comparable to the average distance between the female colonies and potential sires $(5.2 \pm 2.7 \mathrm{~m})$. There was no obvious proximity effect as

Table 4. Pseudopterogorgia elisabethae. Number of planulae sired by successful males at Pillar Reef. Only paternity assignments with probability $\geq 80 \%$ are included

\begin{tabular}{|lccccc|}
\hline \multirow{2}{*}{ Male } & \multicolumn{5}{c}{ Number of planulae sired } \\
\cline { 2 - 4 } \cline { 5 - 6 } & 913 & 924 & 1389 & 1394 & \\
\cline { 2 - 5 } Ba98-610 & & & & \\
Ba98-922 & 0 & 1 & 0 & 1 & 2 \\
Ba98-607 & 1 & 1 & 0 & 0 & 1 \\
Ba98-616 & 1 & 0 & 1 & 0 & 3 \\
Ba98-918 & 0 & 0 & 1 & 0 & 1 \\
Ba99-1374 & 0 & 0 & 1 & 1 & 1 \\
Ba99-1341 & 0 & 0 & 0 & 1 & 1 \\
Ba99-1420 & 0 & 1 & 0 & 0 & 1 \\
Ba99-1376 & 0 & 0 & 1 & 0 & 1 \\
Ba99-1360 & 0 & 0 & 2 & 0 & 2 \\
Ba99-1345 & 0 & 0 & 0 & 1 & 1 \\
Ba98-928 & 0 & 0 & 1 & 0 & 1 \\
Ba99-1413 & 1 & 0 & 0 & 0 & 1 \\
Ba98-909 & 0 & 0 & 2 & 1 & 3 \\
Ba99-1398 & 0 & 0 & 0 & 1 & 1 \\
Ba99-1361 & 0 & 0 & 0 & 1 & 1 \\
Ba99-1401 & 0 & 0 & 0 & 1 & 1 \\
Ba99-1381 & 0 & 0 & 2 & 0 & 2 \\
Ba99-1377 & 0 & 0 & 2 & 0 & 2 \\
Ba99-1352 & 0 & 0 & 0 & 1 & 1 \\
Ba99-1355 & 0 & 0 & 0 & 1 & 1 \\
Ba99-1417 & 0 & 0 & 0 & 1 & 1 \\
Ba99-1392 & 1 & 0 & 0 & 0 & 1 \\
Ba99-1412 & 0 & 0 & 1 & 2 & 3 \\
Ba98-914 & 0 & 0 & 1 & 0 & 1 \\
Ba99-1353 & 0 & 0 & 0 & 1 & 1 \\
\hline
\end{tabular}


many males adjacent to the females were never identified as sires of any planulae (Fig. 1). The colonies that sired more than a single planula on a colony were never the closest colonies. Fig. 1 suggests that sires are found along a dominant axis (lower left to upper right), which might be related to current patterns. The pattern appears stronger in the 1999 data (Females 1389 and 1394) although exceptions to this spatial pattern are apparent.

The logistic regressions, which tested the effects of male colony size and distance to the female colony (Table 5), compared males that sired planulae with those that did not. No significant size or distance effects were identified for the paternity of planulae on any of the 4 female colonies. All of the males included in the analysis were identified, based on the presence of spermaries that were visible with a dissecting microscope. However, we do not know which colonies actually spawned during the 2 spawning events. Thus, the logistic regressions may have included males that did not spawn and could therefore not be sires regardless of their size or proximity to the female colonies. Subse-
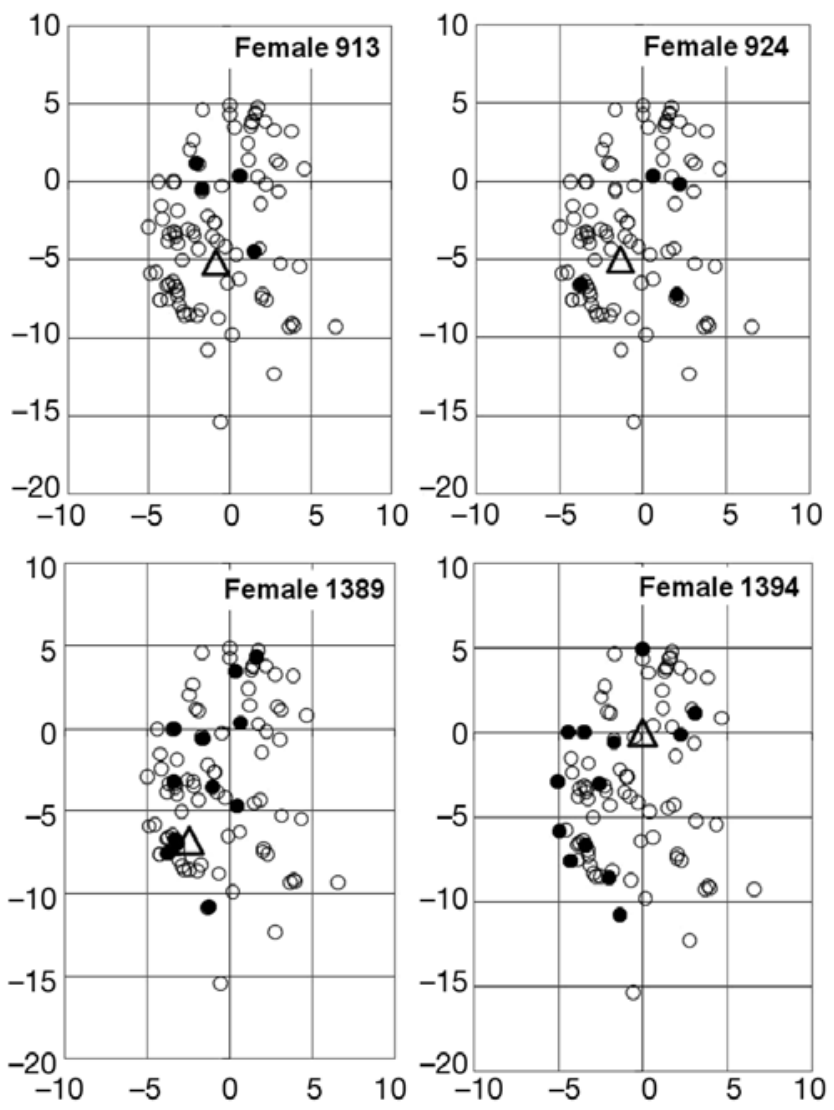

Fig. 1. Pseudopterogorgia elisabethae. Spatial distribution of colonies in the study site at Pillar Reef, San Salvador, Bahamas. $(\mathrm{O}, \mathbf{0})$ Position of males, $(\mathbf{0})$ males that sired planulae, and $(\Delta)$ position of females. Scale on axes in meters
Table 5. Pseudopterogorgia elisabethae. Results of logistic regressions comparing mating success to distance from the female colony, colony height and colony area

\begin{tabular}{|llrrrr|}
\hline & & B & SE & df & Sig. \\
\hline Female 913 & Distance to female & -0.074 & 0.221 & 1 & 0.738 \\
& Height & -0.182 & 0.126 & 1 & 0.149 \\
& Area & 0.001 & 0.003 & 1 & 0.731 \\
& Constant & 0.891 & 2.440 & 1 & 0.715 \\
Female 924 & Distance to female & 0.034 & 0.221 & 1 & 0.879 \\
& Height & 0.100 & 0.094 & 1 & 0.287 \\
& Area & -0.004 & 0.004 & 1 & 0.402 \\
Female 1389 & Constant & -4.654 & 2.484 & 1 & 0.061 \\
& Distance to female & -0.039 & 0.101 & 1 & 0.701 \\
& Height & 0.045 & 0.051 & 1 & 0.384 \\
& Area & 0.000 & 0.001 & 1 & 0.795 \\
& Constant & -2.602 & 1.374 & 1 & 0.058 \\
Female 1394 & Distance to female & 0.052 & 0.110 & 1 & 0.637 \\
& Height & -0.018 & 0.058 & 1 & 0.754 \\
& Area & -0.002 & 0.002 & 1 & 0.334 \\
& Constant & -0.938 & 1.186 & 1 & 0.429 \\
\hline
\end{tabular}

quent analyses were restricted to colonies that were sires in that year, and compared numbers of planulae sired to male colony size and distance. Neither distance nor size had a significant effect on male success when analyzed in that manner ( $p \gg 0.05$ ). The same lack of either a size or distance effect was also observed when Pel-19 and Pel-62, the 2 loci with null alleles, were dropped from the paternity assignment analysis (data not shown).

\section{DISCUSSION}

The presence of null alleles is a potentially biasing factor in parentage analyses based on microsatellites (Dakin \& Avise 2004). Both the heterozygote deficiencies at Pillar Reef and the mismatches of one of the mothers with half of its planulae, provide strong evidence suggesting the presence of a null allele at Pel-19; however, evidence for null alleles at the other loci is limited to the presence of significant heterozygote deficiencies at Pillar Reef (Pel-84) or in other populations (Pel-62; H. R. Lasker \& J. P. Bilewitch unpubl. data). The program Microchecker suggested the presence of null alleles at Pel-19, Pel-32, Pel-62 and Pel-84. The heterozygote deficiencies at the root of the result can be generated by null alleles or by inbreeding within a population or by the Wahlund effect. The present data do not allow us to distinguish between these alternatives. Pel-19 and Pel-62 exhibited heterozygote deficiencies at many other sites and the estimated null frequencies were relatively large. However, heterozygote deficiencies at the other loci at Pillar Reef, which rarely differed from the Hardy-Weinberg equilibrium 
at other sites, may be generated by other processes. Heterozygote deficiencies appear to be especially common among marine invertebrates that cast sperm into the water column (Addison \& Hart 2005). Thus, the presence of heterozygote deficiencies alone cannot be interpreted as a clear indication of null alleles.

Although the presence of null alleles can affect paternity assignments, the parentage analyses using subsets of the data suggest the robustness of the results regardless of the presence of null alleles. Eliminating a locus generally had little effect on the specific paternity assignment and had the primary effect of lowering the likelihoods associated with the specific assignment. The only exception to that pattern was the deletion of the Pel-84 data. Pel-84 exhibited very large numbers of alleles and eliminating it from the analysis dramatically lowered the likelihood of assignments and also changed the assignments for 4 of the planulae. Nonetheless, the overall result, i.e. that almost all of the planulae could have been sired by males in the $20 \times 20 \mathrm{~m}$ area, was not changed by dropping any of the loci from the analysis.

Numerous studies have characterized the reduction in sperm density that occurs as a plume of sperm moves downstream and disperses via eddy diffusion (Denny \& Shibata 1989, Levitan \& Young 1995, Lasker \& Kapela 1997). Fertilization success among broadcast spawning species has also been shown to decrease with increasing distance between males and females (Pennington 1985, Levitan et al. 1992). Similarly, a decrease in fertilization success with increasing malefemale distance was observed by Brazeau \& Lasker (1992) in their examination of a surface brooding species, Briareum asbestinum. These studies along with simulations (Lundquist \& Botsford 2004) have identified a range of conditions under which sperm availability may limit fertilization success in broadcast spawning species.

A corollary to the characterization of sperm dilution and fertilization success is that the most successful males will be those which deliver the greatest numbers of sperm to a female colony. All else being equal, these males should be those that release the most sperm and are closest to a female. Yund \& McCartney (1994) and Yund (1998) reported such a finding for the bryozoan Celleoporella and the tunicate Botryllus schlosseri. The in situ manipulative experiments of Brazeau \& Lasker (1992) and Yund \& McCartney (1994) demonstrated proximity effects, but these effects were observed on scales of $<1 \mathrm{~m}$. In most of these studies, researchers have chosen experimental settings with low adult densities in order to characterize distance and size effects. Furthermore, many experimental designs have limited the time of exposure of eggs to sperm so as not to introduce experimental artifacts.
The relationship between fertilization and male distance and density was less clear in unmanipulated populations of Briareum asbestinum (Brazeau \& Lasker 1992), and no distance effect was observed in the 1 to $20 \mathrm{~m}$ range of the current study. Some of the Pseudopterogorgia elisabethae planulae (20\%) had alleles that did not match any of the genotyped males, but males from within the study area could have sired $87 \%$ of the planulae. Moreover, specific males within the $20 \times 20 \mathrm{~m}$ area were identified as the sires of $25 \%$ of the planulae with $\geq 80 \%$ likelihood. This suggests that while sperm were widely dispersed on scales of 1 to $20 \mathrm{~m}$, there was relatively little successful dispersal of sperm on a larger scale. Thus, sperm dispersal probably has little effect on gene flow in P. elisabethae.

Although the majority of any single female's eggs may have been fertilized by males within the study plot, no single male had particularly great success. Indeed, the number of planulae sired by the different male colonies was not different from random expectations (Kolmogorov-Smirnov comparison to Poisson expectations, $p=0.18$ ). The interpretation of this result must be tempered by the fact that unambiguous paternity could not be determined for the majority of the planulae. This can be attributed to the relatively low allelic diversity among the colonies in the study area. It is likely that additional, highly polymorphic loci would have increased the proportion of paternity assignments, but we cannot preclude the possibility of some size and distance effects. However, the absence of size and distance effects in the analysis that was limited to males that sired planulae, suggests that increased power in the paternity analyses would generate a similar result.

Johnson \& Yund (2007) reported that the density of Botryllus schlosseri colonies did not affect the likelihood that broods were fertilized by multiple males. Ayre \& Miller (2006) also reported patterns consistent with multiple paternity in larvae collected from the brooding scleractinian coral Acropora palifera, and they characterized the pattern as one of random mating. This pattern of random mating also occurred among Pseudopterogorgia elisabethae in a context of high fertilization success, as Lasker (2006) has reported high fertilization success of $P$. elisabethae at Pillar Reef throughout most of the spawning event.

Paternity and fertilization success among Pseudopterogorgia elisabethae populations suggest a model of sperm dispersal and fertilization that differs from the rather dramatic spawning events of many broadcast spawning species. In environments in which many spawning males are distributed over large areas and in which spawning is not compressed into a short time interval, the time-averaged exposure of eggs to sperm may be adequate to effect high rates of fertilization 
even when sperm density is low at any given moment. This may explain the relatively high rates of fertilization that have been reported from at least some natural spawning events (e.g. Sewell \& Levitan 1992, Coma \& Lasker 1997a, Lasker 2006). This accumulation effect may be particularly important for brooding and surface brooding species where eggs continuously 'sample' the water flowing past the colony/individual over the entire length of the spawning event. Meidel \& Yund (2001) found that sea urchin eggs had higher fertilization rates when they were able to 'time average' over $24 \mathrm{~h}$ of naturally occurring spawning events. The effect of time averaging is further magnified among species that actively pump water past eggs, and a number of studies have shown that tunicates can achieve high fertilization rates even when ambient sperm density is low (Bishop 1998, Pemberton et al. 2003).

The expectation that large, nearby males will dominate the paternity of larvae on any single colony initially appears intuitive. However, the random success of males that occurred within an area of at least $400 \mathrm{~m}^{2}$ suggests otherwise and has important implications for our understanding of reproductive systems. Levitan \& Petersen (1995), Yund (1998) and Levitan (2004) have suggested that populations can be placed on a gradient between sperm limitation and sperm competition based on the density and fecundity of males. At one end of the continuum, sperm are limiting and eggs are not all fertilized. These are systems in which selection for traits such as large egg size operates, and Levitan $(2000,2003,2005)$ has extensively discussed the evolution of such mating systems. Surface brooding may represent an adaptation which enhances success not by increasing target size but by increasing the time of egg exposure to sperm (Lasker 2006).

Selection for mating success should also operate on males, and the Pseudopterogorgia elisabethae system presents an interesting case. Paternity was not simply a function of a male being near or producing large numbers of sperm. Success of any given male requires that the sperm are released in the morning when the females release eggs, and currents have to be in the correct direction. While spawning prior to the release of all eggs by females will be disadvantageous, spawning after other males may also be unfavorable. Given the extended accessibility of females, the timing of release may be a crucial component of success. Males that release all of their sperm in a short period risk missing egg availability by being too early or too late in the process. Furthermore, a dense cloud of sperm generated by a rapid release may, until it is diluted, increase polyspermy. A lower-risk strategy may be the steady release of sperm across an extended time period. Sperm released in this fashion would contribute to a pool of sperm from many males which, given sufficient exposure, could generate the high fertilization success of females and the seemingly random success of any single male. Given sufficient information, male success may be 'knowable' as a historic event, but success within proscribed areas may be unpredictable relative to phenotypic traits such as colony size. On the other hand, selection operating on such traits as the timing of sperm release may reduce variance in the success of males and provide more predictable success across the range of environments occupied by $P$. elisabethae colonies.

Acknowledgements. Field work and subsequent analyses were supported by the New York State Sea Grant Institute (Project R/XG-2), the National Undersea Research Center at the Caribbean Marine Research Center (CMRC-99-NRHL01-01C) and the National Science Foundation (OCE 0327129). K. Buchan and the staff of the Gerace Research Centre made our work in San Salvador both productive and enjoyable. C. G.-R. was supported by a IIE/CONACYT/Fulbright-García Robles fellowship. M. Boller, J. A. Sánchez and T. Swain assisted with fieldwork, and L. Bennet, with laboratory work.

\section{LITERATURE CITED}

Addison JA, Hart MW (2005) Spawning, copulation and inbreeding coefficients in marine invertebrates. Biol Lett $1: 450-453$

Ayre DJ, Miller K (2006) Random mating in the brooding coral Acropora palifera. Mar Ecol Prog Ser 307:155-160

Bishop JDD (1998) Fertilization in the sea: Are the hazards of broadcast spawning avoided when free-spawned sperm fertilize retained eggs? Proc R Soc Lond B Biol Sci 265: 725-731

Bishop JDD, Pemberton AJ (2006) The third way: spermcast mating in sessile marine invertebrates. Integr Comp Biol 46:398-406

Brazeau DA, Lasker HR (1992) Reproductive success in the Caribbean octocoral Briareum asbestinum. Mar Biol 114: $157-163$

Coffroth MA, Lasker HR (1998) Larval paternity and male reproductive success of a broadcast-spawning gorgonian, Plexaura kuna. Mar Biol 131:329-337

Coffroth MA, Lasker H, Diamond ME, Bruenn JA, Bermingham E (1992) DNA fingerprinting of a gorgonian coral: a method for detecting clonal structure in a vegetative species. Mar Biol 114:317-325

> Coma R, Lasker HR (1997a) Effects of spatial distribution and reproductive biology on in situ fertilization rates of a broadcast-spawning invertebrate. Biol Bull 193:20-29

> Coma R, Lasker HR (1997b) Small-scale heterogeneity of fertilization success in a broadcast spawning octocoral. J Exp Mar Biol Ecol 214:107-120

Dakin EE, Avise JC (2004) Microsatellite null alleles in parentage analysis. Heredity 93:504-509

Denny MW, Shibata MF (1989) Consequences of surf-zone turbulence for settlement and external fertilization. Am Nat 134:859-889

> Dow BD, Ashley MV (1998) High levels of gene flow in bur oak revealed by paternity analysis using microsatellites. J Hered 89:62-70

Goudet J (1995) FSTAT (Version 1.2): a computer program to calculate F-statistics. J Hered 86:485-486 
Gutiérrez-Rodríguez C, Lasker HR (2004a) Reproductive biology, development, and planula behavior in the Caribbean gorgonian Pseudopterogorgia elisabethae. Invertebr Biol 123:54-67

Gutiérrez-Rodríguez C, Lasker HR (2004b) Isolation and characterization of microsatellite loci in the Caribbean gorgonian Pseudopterogorgia elisabethae. Mol Ecol Notes 4:153-155

Gutiérrez-Rodríguez C, Lasker HR (2004c) Microsatellite variation reveals high levels of genetic variability and population structure in the gorgonian coral Pseudopterogorgia elisabethae across the Bahamas. Mol Ecol 13: $2211-2221$

- Gutiérrez-Rodríguez C, Hannes AR, Lasker HR (2005) Microsatellite variation reveals high levels of genetic variability and population structure in the gorgonian coral Pseudopterogorgia elisabethae across the Bahamas (vol 13, p 2211, 2004). Mol Ecol 14:4205-4206

Johnson SL, Yund PO (2007) Variation in multiple paternity in natural populations of a free-spawning marine invertebrate. Mol Ecol 16:3253-3262

Kalinowski ST, Taper ML, Marshall TC (2007) Revising how the computer program CERVUS accommodates genotyping error increases success in paternity assignment. Mol Ecol 16:1099-1106

Konuma A, Tsumura Y, Lee CT, Lee SL, Okuda T (2000) Estimation of gene flow in the tropical-rainforest tree Neobalanocarpus heimii (Dipterocarpaceae), inferred from paternity analysis. Mol Ecol 9:1843-1852

Lasker HR (2006) High fertilization success in a surfacebrooding Caribbean gorgonian. Biol Bull 210:10-17

Lasker HR, Kapela WJ (1997) Heterogeneous water flow and its effect on the mixing and transport of gametes. In: Lessios HA, MacIntyre IG (eds) Proc 8th Int Coral Reef Symp, Panama 2:1109-1114

Lasker HR, Brazeau DA, Calderon J, Coffroth MA, Coma R, Kim K (1996) In situ rates of fertilization among broadcast spawning gorgonian corals. Biol Bull 190:45-55

> Levitan DR (1991) Influence of body size and population density on fertilization success and reproductive output in a free-spawning invertebrate. Biol Bull 181:261-268

Levitan DR (2000) Optimal egg size in marine invertebrates: theory and phylogenetic analysis of the critical relationship between egg size and development time in echinoids. Am Nat 156:175-192

Levitan DR (2003) Density-dependent sexual selection and the evolution of sexual dimorphism in external fertilizers. Integr Comp Biol 43:915

Levitan DR (2004) Density-dependent sexual selection in external fertilizers: variances in male and female fertilization success along the continuum from sperm limitation to sexual conflict in the sea urchin Strongylocentrotus franciscanus. Am Nat 164:298-309

Levitan DR (2005) Sex-specific spawning behavior and its consequences in an external fertilizer. Am Nat 165: 682-694

- Levitan DR, Petersen C (1995) Fertilization in the sea. Trends Ecol Evol 10:228-231

Levitan DR, Young CM (1995) Reproductive success in large populations: empirical measures and theoretical predictions of fertilization in the sea biscuit Clypeaster rosaceus. J Exp Mar Biol Ecol 190:221-241

Editorial responsibility: Richard Osman,

Edgewater, Maryland, USA
Levitan DR, Sewell MA, Chia FS (1992) How distribution and abundance influence fertilization success in the sea urchin Strongylocentrotus franciscanus. Ecology 73:248-254

> Lian C, Miwa M, Hogetsu T (2001) Outcrossing and paternity analysis of Pinus densiflora (Japanese red pine) by microsatellite polymorphism. Heredity 87:88-98

> Lundquist CJ, Botsford LW (2004) Model projections of the fishery implications of the Allee effect in broadcast spawners. Ecol Appl 14:929-941

Marshall DJ, Steinberg PD, Evans JP (2004) The early sperm gets the good egg: mating order effects in free spawners. Proc R Soc Lond B Biol Sci 271:1585-1589

> Meidel SK, Yund PO (2001) Egg longevity and time-integrated fertilization in a temperate sea urchin (Strongylocentrotus droebachiensis). Biol Bull 201:84-94

Oliver J, Babcock R (1992) Aspects of the fertilization ecology of broadcast spawning corals: Sperm dilution effects and in situ measurements of fertilization. Biol Bull 183: 409-417

Pemberton AJ, Hughes RN, Manriquez PH, Bishop JDD (2003) Efficient utilization of very dilute aquatic sperm: sperm competition may be more likely than sperm limitation when eggs are retained. Proc R Soc Lond B Biol Sci 270:S223-S226

> Pennington JT (1985) The ecology of fertilization of echinoid eggs: the consequences of sperm dilution, adult aggregation and synchronous spawning. Biol Bull 169:417-430

> Petersen CW, Warner RR, Cohen S, Hess HC, Sewell AT (1992) Variable pelagic fertilization success: implications for mate choice and spatial patterns of mating. Ecology 73:391-401

Raymond M, Rousset F (1995) GENEPOP (Version 1.2): population genetics software for exact tests and ecumenicism. J Hered 86:248-249

Sewell MA, Levitan DR (1992) Fertilization success during a natural spawning of the dendrochirote sea cucumber Cucumaria miniata. Bull Mar Sci 51:161-166

> Shearer TL, Gutiérrez-Rodríguez C, Coffroth MA (2005) Generating molecular markers from zooxanthellate cnidarians. Coral Reefs 24:57-66

> Streiff R, Ducousso A, Lexer C, Steinkellner H, Gloessl J, Kremer A (1999) Pollen dispersal inferred from paternity analysis in a mixed oak stand of Quercus robur L. and Q. petraea (Matt.) Liebl. Mol Ecol 8:831-841

van Oosterhout C, Hutchinson WF, Wills DPM, Shipley P (2004) MICRO-CHECKER: software for identifying and correcting genotyping errors in microsatellite data. Mol Ecol Notes 4:535-538

Yund PO (1990) An in situ measurement of sperm dispersal in a colonial marine hydroid. J Exp Zool 253:102-106

Yund PO (1995) Gene flow via dispersal of fertilizing sperm in a colonial ascidian (Botryllus schlosseri): the effect of male density. Mar Biol 122:649-654

Yund PO (1998) The effect of sperm competition on male gain curves in a colonial marine invertebrate. Ecology 79: 328-339

Yund PO, McCartney MA (1994) Male reproductive success in sessile invertebrates: competition for fertilizations. Ecology 75:2151-2167

Yund PO, Murdock K, Johnson SL (2007) Spatial distribution of ascidian sperm: two-dimensional patterns and short vs. time-integrated assays. Mar Ecol Prog Ser 341:103-109

Submitted: February 1, 2008; Accepted: June 13, 2008

Proofs received from author(s): August 28, 2008 